\title{
Preparation of Reference Material 8504, Transformer Oil
}

Dianne L. Poster, Michele M. Schantz, and Stephen A. Wise

National Institute of Standards and Technology,

Gaithersburg, MD, 20899-8392

poster@nist.gov

\author{
A new reference material (RM), RM 8504, \\ has been prepared for use as a diluent oil \\ with Aroclors in transformer oil Standard \\ Reference Materials (SRMs) 3075 to 3080 \\ and SRM 3090 when developing and vali- \\ dating methods for the determination of \\ polychlorinated biphenyls (PCBs) as \\ Aroclors in transformer oil or similar \\ matrices. SRMs 3075-3080 and SRM 3090 \\ consist of individual Aroclors in the same \\ transformer oil that was used to prepare \\ RM 8504. A unit of RM 8504 consists of
}

one bottle containing approximately 100 $\mathrm{mL}$ of transformer oil. No additional constituents have been added to the oil.

Key words: Aroclors; diluent; diluent oil; PCBs; Reference Materials; transformer oil.

Accepted: November 14, 2005

Available online: http://www.nist.gov/jres

\section{Introduction}

A new Reference Material (RM) consisting of transformer oil has been developed. RM 8504, Transformer Oil, is intended to be used as a diluent oil with transformer oil Standard Reference Materials (SRMs) 3075 to 3080 and SRM 3090 [1] when developing and validating methods for the determination of polychlorinated biphenyls (PCBs) as Aroclors ${ }^{1}$ in transformer oil or similar matrices. This suite of Aroclor transformer oil SRMs consists of individual Aroclors in the same transformer oil that was used to prepare RM 8504 and is intended for use in the determination of PCBs in oil. These transformer oil SRMs have been developed to replace SRM 1581, PCBs in Oil, [2] which is no longer available. SRM 1581 was intended for calibrating instruments and validating methods used in the deter-

\footnotetext{
${ }^{1}$ Certain commercial equipment, instruments, or materials are identified in this paper to specify adequately the experimental procedure. Such identification does not imply recommendation or endorsement by NIST, nor does it imply that the materials or equipment identified are necessarily the best available for the purpose.
}

mination of PCBs in motor and transformer oils. The PCBs were present as Aroclor 1242 and Aroclor 1260 in both motor and transformer oil at concentrations near $100 \mu \mathrm{g} / \mathrm{g}$. Two bottles containing approximately $90 \mathrm{~mL}$ each of PCB-free diluent motor oil and transformer oil also were part of a unit of SRM 1581. RM 8504 is intended to replace the diluent transformer oil of SRM 1581. The preparation of RM 8504 is described below.

\section{Materials and Methods}

The transformer oil used in the preparation of this RM was obtained from a commercial source. The RM was prepared at NIST by distributing transformer oil (Univolt 60, Exxon) into $100 \mathrm{~mL}$ amber glass bottles using an automated dispensing machine. The bottles, once filled with approximately $100 \mathrm{~mL}$ oil, were then capped with Teflon-lined screw-caps.

An aliquot of transformer oil from the drum of the Exxon Univolt 60 transformer oil was examined for traces of PCBs as would be evident by capillary gas 
chromatography with electron capture detection (GCECD). The aliquot of oil was first placed on aminopropyl solid phase extraction (SPE) columns, eluted with hexane, concentrated, and analyzed by GC-ECD equipped with a capillary column coated with a nonpolar stationary phase $[5 \%$ (mole fraction) phenyl methylpolysiloxane, DB-5, J\&W Scientific, Folsom, CA].

Additional aliquots from six bottles of RM 8504, selected according to a stratified random sampling scheme, were analyzed by GC-ECD equipped with not only a DB-5 capillary column (described above) but also one with a relatively non-polar stationary phase (DB-XLB, J\&W Scientific, Folsom, CA). Prior to gas chromatography, these samples were processed using analytical methods used for the determination of PCBs in transformer oil. Specifically, samples were placed on aminopropyl SPE columns and eluted with hexane. The concentrated eluants were then fractionated by liquid chromatography using a semi-preparative aminopropylsilane column with hexane as the mobile phase. This is the same approach used for the determination of the concentrations of Aroclors in SRMs 3075 to 3080 and SRM 3090 [1]. Two additional aliquots of RM 8504 were processed as above with the amount of the evaporated extracts targeted to be at a level similar to that obtained during typical oil sample analyses (about 0.2 $\mathrm{g}$, exact mass known). After evaporation, these samples were injected into a GC-ECD equipped with a DB-5 column using splitless injection $(1 \mu \mathrm{L})$ with a split at $0.5 \mathrm{~min}$ at a flow rate of $90 \mathrm{~mL} / \mathrm{min}$ to mimic typical oil sample injections.

Selected Aroclors in transformer oil were analyzed by GC-ECD to determine a detection limit of PCBs, as
Aroclors, in the transformer oil. Aliquots from dilutions of selected Aroclors in transformer oil (SRMs 3077 and 3075 ) with toluene were analyzed directly (no cleanup) by GC-ECD using conditions used for oil analyses [1] and a DB-5 column. These aliquots were injected into a GC-ECD using splitless injection $(1 \mu \mathrm{L})$ with a split at $0.5 \mathrm{~min}$ at a flow rate of $90 \mathrm{~mL} / \mathrm{min}$.

\section{Results and Discussion}

Examination of GC-ECD traces of RM 8504 samples (Fig. 1) demonstrates that PCBs, as Aroclors and as evident by electron capture detection, are not detectable in the oil. Based on the dilutions of selected Arolcor SRMs, it can be stated that Arocolor levels are $<0.1$ $\mathrm{mg} / \mathrm{kg}$ in RM 8504. This value corresponds to $<0.089$ $\mathrm{mg} / \mathrm{L}$ using the reported density of the transformer oil [1]. By comparison, non-PCB waste is classified as those materials that have PCB concentrations $<50$ $\mathrm{mg} / \mathrm{kg}$ by the U.S. EPA [3] and European regulations [4]. Historical (i.e., about 25 years ago) GC-ECD limits of detection reported for PCBs, as Aroclors, in transformer fluids are on the order of $0.5 \mathrm{mg} / \mathrm{kg}$; and for PCBs as total PCBs, limits of detection range from 0.5 $\mathrm{mg} / \mathrm{kg}$ to $1 \mathrm{mg} / \mathrm{kg}$ [5]. More recently, detection limits for selected Aroclors determined by liquid-liquid partitioning followed by headspace solid-phase microextraction and gas chromatography atomic emission detection are reported as $0.5 \mathrm{mg} / \mathrm{L}$ to $1 \mathrm{mg} / \mathrm{L}$ [4]. Given that the concentrations of Aroclors in the transformer oil SRMs [1] range from $(17.1 \pm 1.0) \mathrm{mg} / \mathrm{kg}$ (SRM 3075 , Aroclor 1016 in Transformer Oil) to $(4252 \pm 115)$ $\mathrm{mg} / \mathrm{kg}$ (SRM 3076, Aroclor 1242 in Transformer Oil),



Fig. 1. Example GC-ECD chromatogram of RM 8504, Transformer Oil, from a relatively non-polar column. Sample was first cleaned-up using solid phase extraction and normal phase liquid chromatography. 
the reported less than value of PCBs, as Aroclors, in RM 8504 is well below the concentrations of Aroclors in transformer oil SRMs. RM 8504, used in conjunction with the individual Aroclors in transformer oil SRMs, will be useful to laboratories to underpin accurate determination of the concentrations of individual Aroclors, Aroclor combinations, or PCB mixtures in oils or similar matrices.

\section{Acknowledgments}

The support aspects involved with the certification and issuance of this RM were coordinated through the NIST Measurement Services Division by B. S. MacDonald. The packaging of this RM was facilitated through M. P. Cronise of the NIST Measurement Services Division. Partial support for the development of these SRMs was provided by the U.S. Environmental Protection Agency Office of Water, Office of Enforcement and Compliance Assurance, and Office of Research and Development.

\section{References}

[1] D. L. Poster, M. M. Schantz, S. D. Leigh, and S. A. Wise, Standard Reference Materials (SRMs) for the Calibration and Validation of Analytical Methods for PCBs (as Aroclor Mixtures), J. Res. Natl. Inst. Stand. Technol. 109 (2), 245-266 (2004).

[2] Certificate of Analysis, SRM 1581, Polychlorinated Biphenyls in Oils, National Institute of Standards and Technology, Gaithersburg, MD, www.nist.gov/SRM (1990) [Accessed (11-92005)].

[3] Polychlorinated biphenyls (PCBs) manufacturing, processing, distribution in commerce and use prohibitions, U.S. Environmental Protection Agency, Code of Federal Regulations, 40CFR761, http://www.epa.gov/opptintr/pcb/laws.html (2003) [Accessed (11-9-2005)].

[4] M. R. Criado, I. R. Pereiro, and R. C. Torrijos, Selective determination of polychlorinated biphenyls in waste oils using liquidliquid partition followed by headspace solid-phase microextraction and gas chromatography with atomic emission detection, J. Chromatogr. A 1056 (1-2), 263-266 (2004).

[5] M. D. Erickson, Analytical Chemistry of PCBs, 2nd Ed., CRC Press, Boca Raton (1997); see also references therein.
About the authors: Within the Organic Chemical Metrology Group of the Analytical Chemistry Division in the NIST Chemical Science and Technology Laboratory, D. L. Poster is a research chemist, M. M. Schantz is the team leader of the Gas Chromatography Team, and S. A. Wise is the Chief of the Analytical Chemistry Division. The National Institute of Standards and Technology is an agency of the Technology Administration, U.S. Department of Commerce. 